\title{
Rational policy goals: road safety in Scandinavia
}

\author{
H. Rosencrantz \\ Division of Philosophy, Royal Institute of Technology, \\ Stockholm, Sweden
}

\begin{abstract}
The road safety policy goal in Sweden, as well as the corresponding goals in Denmark and Norway, states that it is unacceptable that anyone is killed or seriously injured as a consequence of road traffic. Although these goals are wellmeant, it could plausibly be asked whether it is rational to have pose such an unrealistic or utopian goals like that of reducing road traffic fatalities and serious injuries to zero. This paper discusses rationality of goals in general, and presents specific criteria for rationality assessment. Several problems with the Swedish road safety policy goal are identified, but it is concluded that it is action-guiding and hence rational.
\end{abstract}

Keywords: road safety, policy goal, rationality.

\section{Introduction}

Vision Zero, Sweden's national road safety policy goal, states that all road traffic fatalities and all serious traffic injuries are to be eliminated; in the long run, no one should be killed or seriously injured as a consequence of road traffic [1-3]. Similar goals have been set in Norway [4] and in Denmark [5]. Soon after Vision Zero was officially adopted by Parliament in October 1997, the goal was supplemented by an interim target, stating that in 2007 the number of killed people on the road should be reduced by at least 50 percent [6-8]. The European Commission has adopted a similar interim target, aiming at a reduction of at least 50 percent during the period from 2000 to 2010 [9].

Although each of these goals is well meant and certainly ambitious, it could plausibly be asked whether it is good to have a policy goal aiming at zero fatalities and serious injuries. It is true, of course, that the reduction of all such 
outcomes would be desirable. But is it rational or ethical to set such a goal as a target for national policy? In particular, three problems seem distressing. First, the goal may be referred to in order to justify implausible prioritisation schemes that prohibit any trade-off between road safety and other policy goals [10]. Second, the goal may be referred to in order to justify unacceptable or at any rate controversial means, such as increased surveillance and driver control [11]. Third, it could be claimed that any utopian goal is illusory and should be excluded from public policy [12]. Although these problems do not follow from Vision Zero itself, or from any of the other Scandinavian road safety policy goals, they explain why there is cause to seriously question whether it is good to have this goal.

The focus of this paper is on rational goal-setting. The paper will start with a discussion on the rationality of goals in general, and the rationality of policy goals in particular. After that follows a brief presentation of an independently formulated theory of rational goal-setting. The rest of the paper will be devoted to analysing Vision Zero, the Swedish road safety goal, and the corresponding goals in Denmark and Norway. It is concluded that Vision Zero is not irrational, since it satisfies a set of criteria for being an action-guiding goal.

\section{What is a rational goal?}

What does it mean to say that a goal is rational or irrational? An often accepted view is that actions are rational if (and, perhaps, only if) they contribute to the achievement of the agent's goals. In this sense, therefore, actions are rational relative to goals. Goals themselves, however, can be completely arbitrary on this account [13]. Related approaches are to see goals as similar to individual tastes, in the sense that they are what they are, or to see reason as wholly instrumental [14]. In particular, if rationality is defined relative to goals, then it would be meaningless to speak about rational goals in the first place.

One exception to the last statement would be inconsistency. Goals can be said to be irrational when they are contradictory, or in some other way stand against each other. Three distinct cases of inconsistency can be identified. Logical inconsistency of goals certainly seems irrational, but would be rare. It would be irrational to set a goal to reduce road traffic fatalities to zero while at the same time set another goal to increase road traffic fatalities to a number greater than zero, but cases of this kind are rare in practice. Contingent inconsistency of goals may be more common, but it is doubtful whether such inconsistency ought to count as irrationality. A goal to reduce road traffic fatalities to zero may be in conflict with an accessibility goal to make people able to drive faster on the roads, or safety may in some other way be in conflict with accessibility, but mere goal conflict is not a sign of irrationality. Self-defeating inconsistency may also be common in real life, and is certainly something one should avoid, but it pushes the issue of rational goals aside since it treats goals as means to achieve other goals or as specifications of other goals rather than as ends in themselves. A goal to reduce road traffic fatalities to zero may defeat the goal to reach the socially optimal number of road traffic fatalities, given that resources available 
for safety measures are scarce and that there is demand for organ transplants, but this relation is reduced to mere conflict unless one goal is viewed as a means or a specification of the other.

Notably, these three cases of inconsistency refer to systems of more than one goal. Can a goal be inconsistent by itself? Perhaps inconsistency is the wrong term here, but a goal - by itself - can clearly be self-defeating in a contingent way. (A goal may also be illogical in its own right. Such peculiar goals are, however, not worth discussing at length here; consider, for example, the goal to "Design a transport system that is safer than itself.") The goal to advance one's own individual interests is self-defeating, since, taken as a general principle, it often leads to people having more frustrated interests than they would have had they not pursued the goal; and similarly, the goal to attain the greatest possible societal well-being is self-defeating, since, taken as a general principle, it demands too much of individuals and would make their aggregated well-being less than it would be had they not pursued the goal [15].

The last point leads the discussion to collective, or political, goals - such as policy goals. In a society, whether it is small or large, each individual has his or her own goals - which do not necessarily need to be goals of self-interest in the narrow sense. In addition, groups or parties within the society have their own goals. For societal goals, it could be demanded that they should also be consistent with the other goals in society. Naturally, it is sometimes hard to find a common goal that everyone finds desirable, or even acceptable [16]. This is not to say that goals across individuals are generally suspicious, and should be avoided if possible, but it gives us reason to reconsider and means to explain the rationality of political goals. If the setting of collective goals is a process of strategic interactions between different agents, then it quite conceivable that such a goal may be rational for some and irrational for others. Whether it is rational for the collective remains an open question. A regional goal, aiming at offsetting disadvantages of long travel distances in sparsely populated areas, may be rational for those living in such areas but not for others; a good-willed politician, who wants to reach fame as a champion of the environment, may strive to institute environmental targets far more ambitious than what is actually economically efficient; and equally well-meaning engineers and scientists, in pursuit of new but possibly very expensive challenges, may press for the adoption of national transport policy goals to promote superior technical quality.

Whether or not a goal is rational, then, is by no means always a question with an unambiguous answer. But at least it appears to be a meaningful question. The next section will be dedicated to presenting general rationality criteria, as developed independently elsewhere, for a goal taken as an end in itself and not in relation to other goals.

\section{When is a goal rational?}

In order to be meaningful, a goal must guide actions. This is what might be called achievement-inducing. If a goal is set in order to be achieved, it is rational only if it is achievement-inducing. For the goal of an individual, the property of 
being achievement-inducing means that the goal must guide the individual's actions over time. And for the goal of several individuals, the property of being achievement-inducing means that the goal also must guide actions across individuals and function as a way of communication.

Not all goals are achievement-inducing. In order to have this property, it has recently been argued that a goal must satisfy four criteria; it must be precise, evaluable, approachable, and motivating [17]. These criteria are obviously not absolute, since a goal can be more or less precise and more or less approachable, etc. We might therefore refer to a goal as more or less rational, in the sense of being more or less achievement-inducing, depending on the extent that the four criteria are satisfied. It clearly appears, however, that the criteria are necessary for a goal to guide actions and hence to be rational.

Precision means that a goal is free from vagueness and arbitrary terms. If a goal is not precise, then it will fail to guide actions. An imprecise goal, such as "Achieve a better society", will be meaningless unless specified further. Evaluability means that performance of a goal can be measured in some way or another. A goal will not be meaningful if there is no way to tell whether it has been achieved or approached. An example might be a goal to decrease pollution to a level so low that it cannot be measured accurately. Approachability means that performance is possible. Since approachability does not require achievability, on this account, a goal can be achievement-inducing without being achievable. This is not entirely implausible; utopian goals may be rational, in the sense that they inspire and communicate commitments to action, without being achievable. Motivity, finally, means that the goal should motivate actions that further the achievement of the goal. A goal is not achievement-inducing if no agent wants to perform the necessary tasks.

Achievement-induction may therefore be viewed as a property of four dimensions - one for each criterion. Clearly, there are situations where these dimensions need to be traded against one another; a vague or difficult goal may not be very precise or approachable, but such goals are often highly motivating. However, there is no obvious way to evaluate such trade-offs. It may therefore prove difficult to say whether one goal is more or less rational than another, but weak dominance - i.e., that a goal is at least as rational as another if it satisfies each of the four criteria at least as good - appears a plausible minimal condition. Rather than using the criteria as a means for ranking goals in terms of rationality, however, they may be used in order to identify strengths and weaknesses of goals, to identify problems, and to point out how whether a given goal could be formulated in a better way.

\section{Is Vision Zero a rational goal?}

Taking the four criteria mentioned in the previous section into consideration, a number of problems for Vision Zero can be identified. These problems seem to suggest that the goal could have been formulated in a better way.

Vision Zero is precise in the sense that it specifies in what direction to go in order to approach the goal, and it is precise also in the sense that it tells the agent 
to what extent the goal should be reached; Vision Zero tells us that, in order to achieve the goal, road traffic fatalities and serious traffic injuries should decrease until the numbers reach zero. However, Vision Zero does not tell us when the goal is supposed to be achieved. As mentioned earlier, the interim target of a 50 percent reduction is supposed to be achieved before the year 2007, but there is no deadline before which Vision Zero itself is supposed to be achieved. Obviously, since there is no deadline, it will never be too late to achieve the goal of zero dead and serious injuries in road traffic. A fifty percent reduction, as stated by the interim target, means a reduction from 540 to 270 annual deaths during the period 1997-2007. In 2005, there were still 440 fatalities [18]. If the interim target fails to be achieved, then it can always be replaced by a new and less ambitious interim target. This would not be inconsistent with Vision Zero, and the lack of temporal precision may entail the danger of stagnation and loss of ambitiousness.

Vision Zero is evaluable in the sense that it performance and progress can be measured in terms of reductions of road traffic fatalities and serious injuries. On the other hand, it does not tell us how to compare these two aspects of road safety. It is true that the number of fatalities has been reduced since the goal was adopted, but the number of serious injuries remains about the same and has for a long time even been significantly higher than it was in 1997. Have we come closer to achieve the goal? And how much closer? These questions cannot be answered without specifying how fatalities should be compared to serious injuries. This is possible, of course, by using common measures such as willingness-to-pay or quality adjusted life years. But the goal itself does not say that any such means of comparison should be applied.

Although Vision Zero may appear utopian and unrealistic, approachability is perhaps the least problematic feature of the goal. The goal of zero fatalities and serious injuries may not be achievable, but there certainly are many ways in which the situation could be made better than it is today. This being said, it could also be pointed out that there are many supposedly rational goals, such as the political ideals of liberty and justice, that appear unrealistic but still may serve to guide actions over time and across agents - i.e., be action-guiding.

Without further empirical observations, it may be hard to check whether Vision Zero is sufficiently motivating. When a utopian or unrealistic goal is used as a standard to which performance is compared, however, the discrepancy between the goal and the agent's actual performance is generally so great that it does not create a corrective motivation to change the agent's behaviour towards the goal $[19,20]$. A goal that is too difficult may therefore become counterproductive. Whether this is true for Vision Zero is left open for now.

Thus, Vision Zero has several problematic features. However, since the four criteria cannot be assumed to be entirely independent, it would be a too hasty conclusion to say that it should have been formulated differently. Generally, evaluability presupposes precision. And in this case, the lack of temporal precision may be necessary to provide flexibility and to maintain motivity as well as approachability. Therefore, although problems of rationality can be identified, it is hard to say whether Vision Zero should be formulated differently. 
Since it apparently satisfies all of the four criteria, at least minimally, it is achievement-inducing and hence rational.

\section{Conclusion}

Although rationality is often defined relative to goals, it is meaningful to ask whether a goal itself is rational. A basic criterion of a meaningful goal is that it should be action-guiding, which requires that it should be precise, evaluable, approachable, and motivating. With respect to these four conditions, Vision Zero is a rational goal.

\section{References}

[1] Government Bill 1996/97:137 Nollvisionen och det Trafiksäkra Samhället [Vision Zero and the Traffic Safe Society].

[2] Committee Report 1997/98:TU4 Nollvisionen och det Trafiksäkra Samhället [Vision Zero and the Traffic Safe Society].

[3] Riksdag Communication 1997/98:11.

[4] Steinset, B.K., P.O. Wanvik, I. Handorsen, A.K. Midtgaard, R. Muskaug, and B. Skaugset (2002) Nasjonal Handlingsplan for Trafikksikkerhet på Veg 2002-2001 [National Strategy Plan for Road Safety 2002-2011]. Vegdirektoratet, Oslo.

[5] Færdselssikkerhedskommissionen [Danish Road Safety Commission] (2002) Hver Ulykke er én for Meget - Trafiksikkerhed Starter med Dig [Every Accident is one too Many - Traffic Safety Starts with You]. Trafikministeriet, Copenhagen.

[6] Government Bill 1997/98:56 Transportpolitik för en Hållbar Utveckling [Transport Policy for a Sustainable Development].

[7] Committee Report 1997/98:TU10 Transportpolitik för en Hållbar Utveckling [Transport Policy for a Sustainable Development].

[8] Riksdag Communication 1997/98:266.

[9] Peden, M., R. Scurfield, D. Sleet, D. Mohan, A.A. Hyder, E. Jarawan, and C. Mathers (eds.) (2004) The World Report on Road Traffic Injury Prevention. World Health Organization, Geneva.

[10] Elvik, R. (1999) 'Can injury prevention efforts go too far? Reflections on some possible implications of Vision Zero for road accident fatalities', Accident Analysis and Prevention, 31(3), pp. 265-286.

[11] Ekelund, M. (1999) Varning - Livet Kan Leda till Döden! [Warning Life Can Lead to Death!]. Timbro, Stockholm.

[12] Lind, G. and K. Schmidt (1999) Leder Nollvisionen till det Trafiksäkra Samhället? [Does Vision Zero Lead to a Traffic Safe Society?]. Kommunikationsforskningsberedningen, Stockholm.

[13] Allais, M. (1953 [1979]) 'The foundations of a positive theory of choice involving risk and a criticism of the postulates and axioms of the American school', pp. 27-145 in Allais, M. and O. Hagen (eds.) Expected Utility Hypotheses and the Allais Paradox. D. Reidel, Dordrecht. 
[14] Simon, H. (1983) Reason in Human Affairs. Basil Blackwell, Oxford.

[15] Parfit, D. (1984) Reasons and Persons. Clarendon Press, Oxford.

[16] von Hayek, F.A. (1944) The Road to Serfdom. G. Routledge \& Sons Ltd., London.

[17] Edvardsson, K. and S.O. Hansson (2005) 'When is a goal rational?', Social Choice and Welfare, 24(2), pp. 343-361.

[18] Brüde, U. (2005) Basstatistik Över Olyckor och Trafik samt andra Bakgrundsvariabler [Basic Data of Accidents, Traffic, and Other Fundamental Variables]. Väg- och Transportforskningsinstitutet, Stockholm.

[19] Campion, M.A. and R.G. Lord (1982) 'A control systems conceptualization of the goal-setting and changing process', Organizational Behaviour and Human Performance, 30, pp. 265-287.

[20] Stedry, A.C. and E. Kay (1966) 'The effects of goal difficulty on performance: A field experiment', Behavioural Science, 11, pp. 459-470. 